\title{
In world of epidemics, WHO's in control
}

Last year's outbreak of severe acute respiratory syndrome (SARS) provided the World Health Organization (WHO) an opportunity to show the world its teeth. Newly installed directorgeneral Jong-Wook Lee intends to use them to take a bite out of the world's costliest diseases.

In recent months, Lee has sounded a clarion call for the WHO to lead a scale-up of AIDS treatment and other targets spanning a wide spectrum - from eradicating polio to curbing tobacco use, combating cardiovascular disease, and significantly reducing childhood mortality.

But the WHO's new stances on SARS and HIV/AIDS have by far received the most attention. The organization has updated guidelines for AIDS treatment and redoubled its commitment to providing antiretroviral therapy to 3 million people (of the 6 million who need it) worldwide by 2005 - a $\$ 5.5$ billion initiative.

The rapid emergence and spread of SARS stirred something of a crisis mentality. Through its Global Outbreak Alert and Response Network, the WHO- under former directorgeneral Gro Harlem Brundtland-responded by deploying epidemiologists and other experts throughout the world. The experts pieced together their findings in Geneva during daily teleconferences, resulting in the eventual identification of the mysterious coronavirus.

More controversial were the advisories against travel to Toronto, Hong Kong and parts of China, providing an unprecedented illustration of the WHO's singular discretion.

"I didn't realize until later that that was the first time [travel advisories had ever been issued]," says Ray Arthur, associate director for global health at the US National Center for Infectious Diseases. "If you look at it from the perspective of what measures needed to be taken, it's not a surprise," he adds.

The WHO is now trying to draw on the clout it gained during the SARS epidemic to foster similar urgency in battles against HIV/AIDS and other long-entrenched enemies.

"We looked very hard at the SARS example and we realized that you can do this and you can survive it and have a very real impact," says Jim Yong Kim, an advisor to Lee in Geneva. Previous recommendations for AIDS treatment took years to adopt and prescribed dozens of protocols-such as CD4 counts and the measurement of viral loads-that made treatment prohibitive to a large part of the world, Kim says.

In a matter of just months, the organization developed new guidelines incorporating models such as Haiti's HIV Equity Initiative. "Up to now," Kim says, "what we have done has been much too complicated and much too slow."

Lee's tenure has been marked by such emphasis on activist, ground-level goals, but his biggest challenges, say some observers, could lie in galvanizing the member states.

"I don't think [the WHO] has the resources yet to manage that," says epidemiologist Ernest Drucker of Montefiore Medical Center in New York. The WHO remains dependent on its member states to commit material, financial and ideological backing. Channeling diverse, and occasionally competing, agendas, Drucker says, is often a tall order.

Others point to a heightened sensitivity to international health. "Any time there's a major epidemic, obviously it attracts a lot of attention from the public," says Arthur. "You perform well when you're under the spotlight, and that's recognized; you don't perform well, and there are probably some consequences."

Bruce Diamond, New York

\section{US soldiers refuse to fall in line with anthrax vaccination scheme}

US soldiers are battling with the federal government over the military's anthrax vaccination scheme. After a flurry of rulings and counterrulings over whether the vaccine can protect soldiers from inhalation anthrax, a federal court in January lifted a temporary ban on the program. But the debate over the drug's efficacy is likely to continue as the case moves through the courts.

The US has vaccinated more than a million soldiers since 1998. Opponents of the program say the vaccine causes both long- and shortterm health problems, including pneumonia, joint pain and gastrointestinal disorders.

Thousands of adverse event reports have been filed with the US Food and Drug Administration (FDA). However, based on existing evidence, several scientific panels have determined that the vaccine is safe. Those who refuse the shot have been disciplined and, in some cases, court-martialed.

No one argues that the vaccine is effective against cutaneous anthrax. A 1962 study-the only placebo-controlled human trial of the anthrax vaccine-followed 1,200 workers in four textile mills. Only 1 of the 26 subsequent cases of anthrax occurred in a fully vaccinated worker, but only 5 of the 26 cases were of inhalation anthrax (Am. J. Public Health 52,

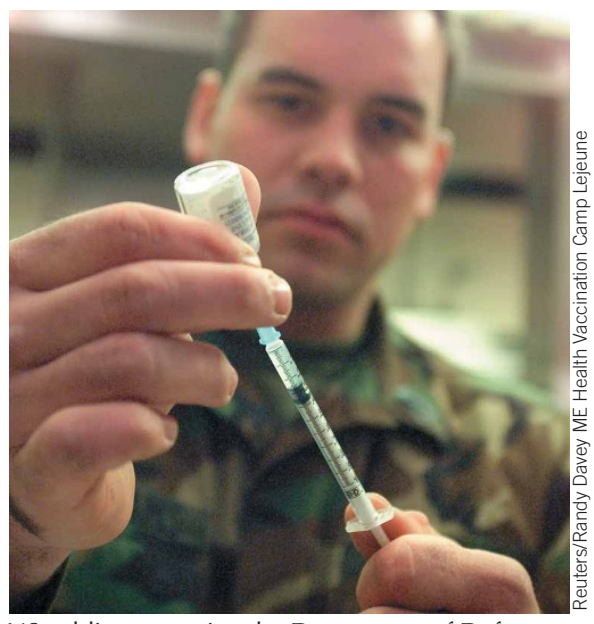

US soldiers are suing the Department of Defense over forced vaccinations.

632-645; 1962). Based on those data, a scientific panel in 1973 concluded that inhalation anthrax "occurred too infrequently" to assess the vaccine's efficacy against it.

The panel's recommendations languished in regulatory limbo, however. They were finally published in 1985, but the FDA never formally adopted or rejected them. In his initial ruling, Judge Emmett Sullivan said the vaccine is an investigational drug being used for an unapproved purpose. He ruled that the US "cannot demand that members of the armed forces also serve as guinea pigs for experimental drugs."

One week later, the FDA published a belated analysis of the 1985 recommendations, disputing the panel's finding. Analyzing the two exposure routes together, it concluded the vaccine is 92.5\% effective against all forms of anthrax.

Based on the FDA's new analysis, the judge lifted the temporary ban. But the new interpretation of the data is a matter of semantics, not science, argues Gene Stollerman, who chaired the 1973 panel. "I will defend our interpretation," Stollerman says. "Any other interpretation has to do with legal issues."

The existing evidence doesn't meet the FDA's usual standards, adds Mark Zaid, the Washington-based lawyer who brought the case against the US Department of Defense (DOD). "When had the FDA ever said to anyone, 'it's probably effective so we're going to give you a license'?" Zaid asks.

Confident it will prevail, the DOD has ordered a $\$ 30$ million batch of the vaccine. Laywers for the soldiers, meanwhile, have asked the judge to grant the case class-action status.

Tinker Ready, Boston 